\title{
RECICLO CELULAR DE Zymomonas mobilis EM SISTEMA DE MEMBRANAS
}

\author{
P.F. FOREST ${ }^{1}$, M. GIRARDI ${ }^{1}$, C. REGINATTO ${ }^{1}$, V. DOS SANTOS ${ }^{2}$, M. ZENI ${ }^{2}$, E. \\ MALVESSI $^{1}$ \\ ${ }^{1}$ Universidade de Caxias do Sul, Instituto de Biotecnologia \\ ${ }^{2}$ Universidade de Caxias do Sul, Departamento de Química \\ E-mail para contato: pfforest@ucs.br
}

RESUMO - Para a obtenção de altos rendimentos em biomassa e etanol em cultivos de Zymomonas mobilis, têm sido empregadas técnicas de reciclo celular, com destaque para a utilização de membranas. Neste trabalho foi comparado o reciclo de células através de sistemas de membranas cerâmica e poliméricas (fibras ocas). Z. mobilis foi cultivada em reator de $0,5 \mathrm{~L}$. Ao final da batelada, o caldo fermentado foi introduzido nas membranas até o esgotamento. As células foram então re-introduzidas no reator, iniciando nova fermentação. Incremento médio de $38 \%$ na concentração celular foi atingido com o uso de membrana cerâmica. Por outro lado foi observada queda em termos de biomassa com uso de fibras ocas devido à dificuldade de reciclo total. Consequentemente, maiores conversões de substrato em células e em etanol foram atingidas com membrana cerâmica, sendo nas condições testadas, a alternativa mais indicada para este propósito.

\section{INTRODUÇÃO}

Zymomonas mobilis, bactéria anaeróbia, Gram negativa, tem merecido destaque na produção de etanol em larga escala frente ao uso de leveduras por apresentar características como a tolerância a altas concentrações de açúcares e etanol e relativa resistência a meios ácidos e contaminações. Como fontes de carbono para crescimento e produção de etanol, Z. mobilis utiliza glicose, frutose e sacarose, sendo que rendimento em etanol superior à $90 \%$ é obtido com o emprego de glicose como substrato (SWINGS \& DE LEY, 1977; VIIKARI, 1988; ERNANDES, 2009).

Para a obtenção de células/enzimas e elevados teores de etanol por Z. mobilis, inicialmente é conduzida a etapa fermentativa. Ao final do cultivo, em função de dificuldades em termos de separação da biomassa do meio de fermentação - que restringe o uso de centrífugas devido à pequena dimensão das células bacterianas - tem sido relatado o emprego de membranas, com o intuito de separar in situ os produtos da fermentação. Em função disso, abre-se a possibilidade do emprego de processos envolvendo membranas para a separação e concentração dos produtos da fermentação, como forma alternativa à centrifugação ( JULBE et al., 2001; CARSTENSEN et al., 2012). Os processos de separação por membranas tais como a microfiltração, ultrafiltração e 
osmose inversa, consolidaram-se em diferentes setores industriais, por proporcionarem simplicidade no modo operacional e no escalonamento, podendo ser incorporados em processos biotecnológicos. A principal característica que distingue estes processos de outras técnicas de separação é o uso de membranas seletivas em módulos compactos e em condições de baixo consumo de energia (BAKER, 2004, XU et al., 2005).

Neste contexto, este trabalho teve como objetivo conduzir os cultivos de Z. mobilis com posterior reciclo de células, através de módulo de membrana cerâmica tubular ou de membrana polimérica de fibras ocas, visando ao aumento de produção de biomassa e rendimento em etanol.

\section{MATERIAL E MÉTODOS}

\subsection{Microrganismo e condições de cultivo}

A linhagem bacteriana usada neste estudo foi Zymomonas mobilis ATCC 29191. O meio líquido utilizado para conservação, obtenção de inóculo e ensaios em biorreator continha, em sua composição, 20, 100 e 80g/L de glicose, para ativação das células, inóculo e cultivos em biorreator respectivamente, e demais sais nutrientes. O fermentador utilizado em todos os experimentos possuía volume útil de $0,5 \mathrm{~L}$, em regime descontínuo, a $30^{\circ} \mathrm{C}, \mathrm{pH}$ controlado em 5,5 pela adição automática de $\mathrm{NaOH}$ 2,5mol/L, sob agitação magnética.

\subsection{Reciclo de células através de membranas}

Ao final de cada batelada, as células foram concentradas nas membranas e o permeado foi separado para posterior determinação de etanol. As células retidas nas membranas foram removidas pela passagem de água em fluxo invertido e reintroduzidas no reator.

Os testes foram realizados com a utilização de uma membrana cerâmica de $\alpha$-alumina, fornecida pela Tecnicer-Cetebra (São Carlos/SP), conformada na forma de tubo microporoso (tamanho médio de poros de $0,64 \mu \mathrm{m}$ ) com diâmetros interno de $8 \mathrm{~mm}$ e externo de $12 \mathrm{~mm}$ e 210 mm de comprimento. $\mathrm{O}$ módulo de membrana polimérica de poli (éter imida) foi fornecida por PAM membranas (Rio de Janeiro/RJ), conformadas na forma de fibras ocas (tamanho médio de poros de $0,4 \mu \mathrm{m}$ ), inserida no tubo de policloreto de vinila (PVC).

O sistema empregado no reciclo de células através de membranas foi composto de bomba de diafragma, manômetros e módulo de membrana, este último acoplado externamente ao reator.

\subsection{Caracterização das membranas}

As membranas foram caracterizadas através dos testes de microfiltração, determinando a compactação, permeabilidade à agua. As quantificações do fouling e de polarização foram realizadas por balanço de massa (MANTTARI et al., 2006). 
As membranas foram, posteriormente, submetidas à limpeza em banho ultrassônico por 30 min, alternando a imersão em solução aquosa $0,5 \%(\mathrm{~m} / \mathrm{v})$ de ácido cítrico e $0,1 \mathrm{~mol} / \mathrm{L}$ de hidróxido de sódio.

\subsection{Metodologia analítica}

A concentração celular foi determinada pela medida da absorbância, a 560nm, em espectrofotômetro (Aurora Instruments UV-210). A concentração de açúcares redutores foi quantificada pelo método do ácido 3,5-di-nitro-salicílico-DNS (MILLER, 1959). A quantificação do etanol do caldo de fermentação foi determinada, após a destilação, em equipamentos acoplados Densimat e Alcomat (Gibertini, Italy).

\section{RESULTADOS E DISCUSSÃO}

Para a condução dos testes com a membrana cerâmica, esta foi acondicionada dentro de um módulo construído em aço inoxidável e adaptado externamente ao biorreator. $\mathrm{O}$ caldo a ser permeado era direcionado à bomba de diafragma e em seguida conduzido ao interior da membrana, onde escoava pela parte interna da mesma. $O$ permeado, isento de células de Z. mobilis, escoava pela parte externa da membrana. $O$ caldo não permeado retornava ao fermentador através da corrente do concentrado.

Em relação às membranas poliméricas de fibras ocas, estas estavam acondicionadas em um módulo de PVC. Neste caso, a corrente de células entrava na parte externa das fibras ocas, escoando pela carcaça, e permeava para o interior, axialmente.

As áreas de permeação das membranas cerâmica e polimérica era de 0,01 e $0,027 \mathrm{~m}^{2}$, respectivamente, sendo empregada a velocidade tangencial de $1,5.10^{-6} \mathrm{~m} / \mathrm{s} \mathrm{em}$ ambas as condições.

\subsection{Características das membranas}

No teste de compactação, comportamento similar foi observado para ambos os tipos de membranas. O processo de permeação da água destilada iniciava com fluxo alto de permeado, que decrescia até valores constantes, comportamento esse indicativo da compactação das membranas.

Em ambos os sistemas testados, o tempo de compactação foi semelhante, cerca de 3 horas, porém o fluxo permeado pela membrana cerâmica foi 2,5 vezes maior do que o obtido na membrana polimérica, possivelmente devido ao maior tamanho de poros da membrana cerâmica em comparação à membrana de fibras ocas (Figuras 1A e 1B). 


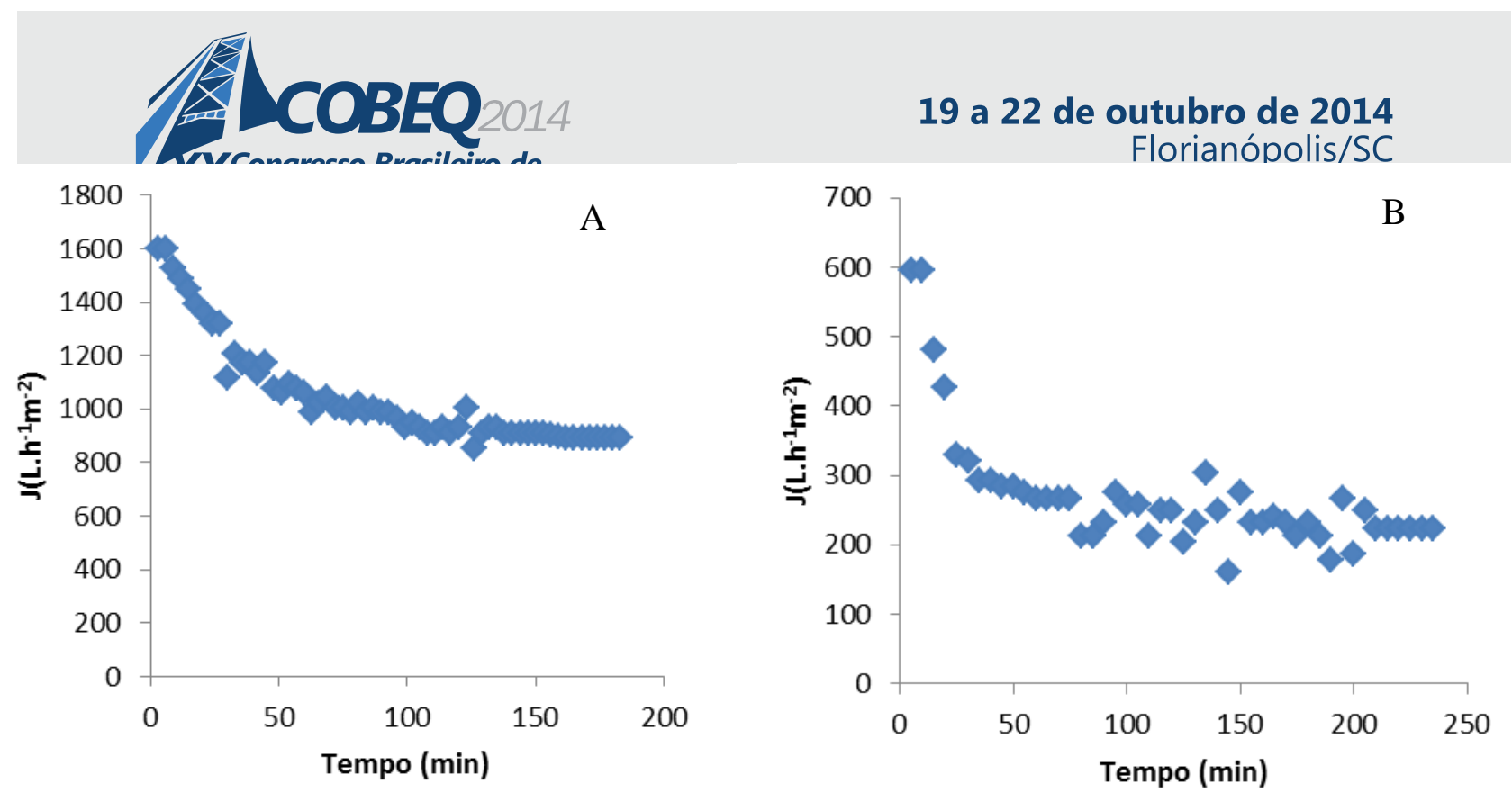

Figura 1: Compactação do módulo de membrana cerâmica tubular, à pressão de 6 bar (A) e do módulo de membrana polimérica de fibras ocas, à pressão de operação de 3 bar (B).

A permeabilidade hidráulica foi determinada para ambas as membranas a $25^{\circ} \mathrm{C}$, sendo definida em função da declividade da reta, resultante da função gráfica entre o fluxo permeado $(\mathrm{J})$ e a pressão de operação. Foi verificado o aumento da resistência proporcionalmente à pressão aplicada, independente do tipo de membrana utilizada (Figuras 2A e 2B).
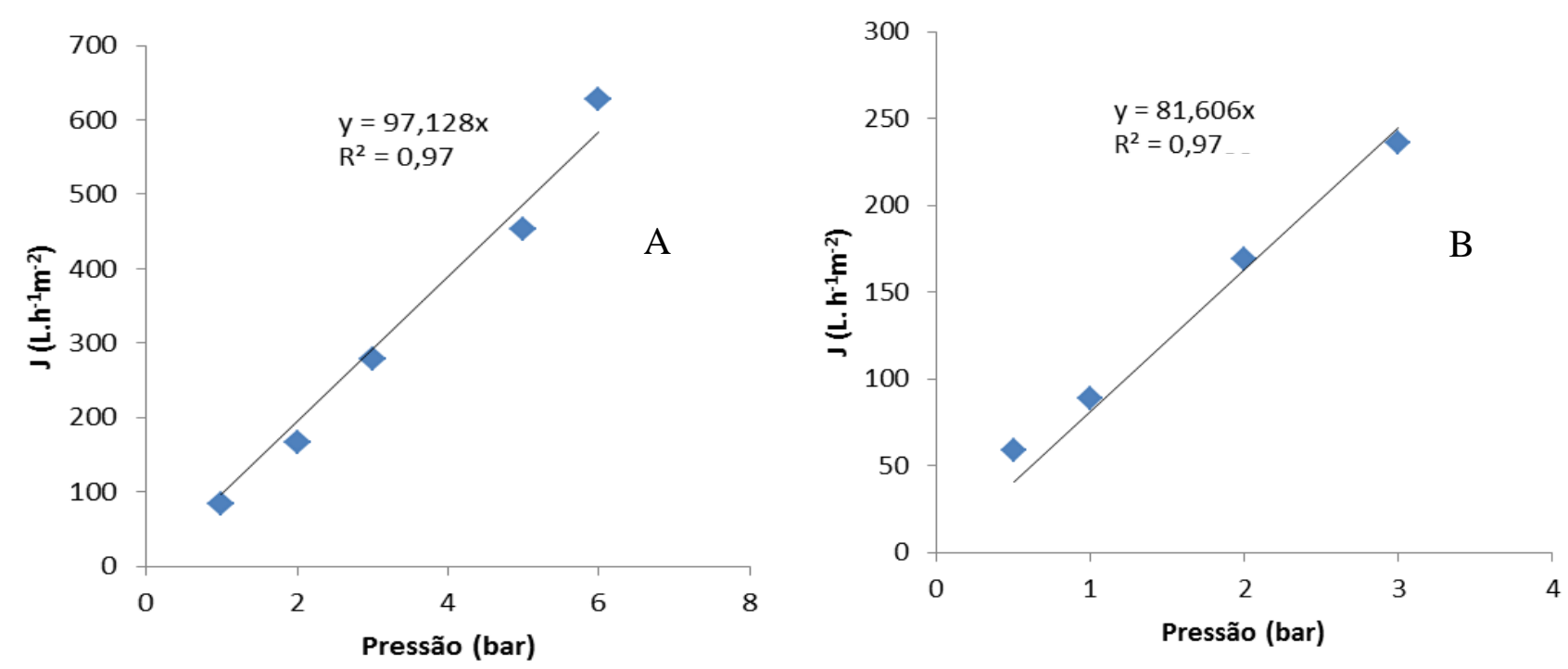

Figura 2. Permeabilidade hidráulica da membrana cerâmica tubular (A) e da membrana polimérica de fibras ocas (B), relacionando os respectivos fluxos de permeado e pressões de operação.

Como observado na Figura 2, maior permeabilidade hidráulica foi atingida nos testes realizados com a membrana cerâmica quando comparado com a membrana polimérica, de 97,12 

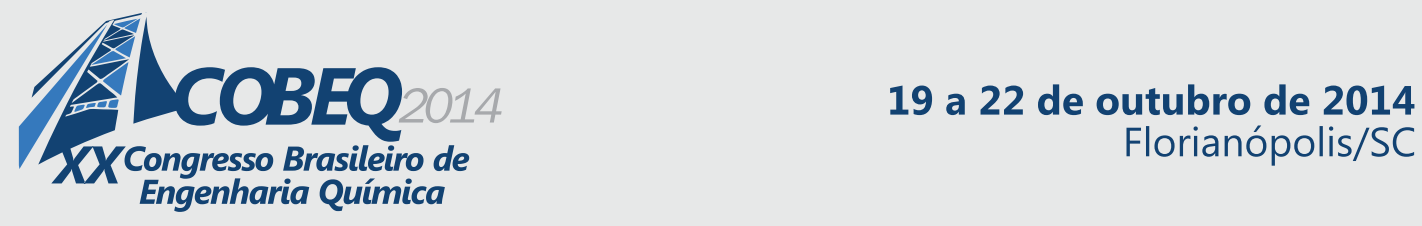

e 81,6 L.m ${ }^{-2} \cdot \mathrm{h}^{-1} \cdot$ bar $^{-1}$, respectivamente, devido à maior porosidade da membrana cerâmica, permitindo assim maior passagem da água a ser permeada.

Em estudos de caracterização de membranas cerâmicas tubulares, Diel et al. (2010) relatam a obtenção de 99 e $186 \mathrm{~L} \cdot \mathrm{m}^{-2} \cdot \mathrm{h}^{-1} \cdot$ bar $^{-1}$, respectivamente, para membranas cerâmicas de $\alpha$-alumina de 0,1 e 0,4 $\mu \mathrm{m}$ de tamanho de poro. Wallberg et al. (2003) relatam a obtenção de valores de permeabilidade hidráulica para membranas cerâmicas, na ordem de $90 \mathrm{~L} \mathrm{~h}^{-1} \mathrm{~m}^{-2^{3}}$. Tais membranas foram usadas em experimentos de ultrafiltração e apresentavam massa molecular de corte de 15 KDa.

\subsection{Fermentações com reciclo de células através de membranas cerâmicas}

Em se tratando de utilização das membranas na etapa de reciclo de células e separação de etanol, inicialmente foi realizada a fermentação em biorreator e, ao final do processo, este foi permeado pela membrana cerâmica até o seu esgotamento. Posteriormente, as células retidas na membrana foram recirculadas para o interior do fermentador, iniciando nova batelada. Para o primeiro reciclo, o tempo de permeação na membrana foi de cerca de $3 \mathrm{~h}$ e para o segundo, de $4 \mathrm{~h}$. A compilação dos principais resultados é apresentada na Tabela 1.

Nos cultivos visando ao reciclo de células através da membrana cerâmica foram observados aumentos médios de 48 e $51 \%$ na concentração celular no primeiro e no segundo ensaio, respectivamente, calculados entre a primeira e a terceira batelada. Em termos de produto, foi observada uma tendência de aumento de cerca de $10 \%$ entre os reciclos (Tabela 1).

Tabela 1. Resultados gerais dos ensaios de fermentação de Zymomonas mobilis com reciclo de células através de membrana cerâmica tubular $\left(\mathrm{S}_{0}=80 \mathrm{~g} / \mathrm{L}, \mathrm{pH} 5,5,30^{\circ} \mathrm{C}\right)$.

\begin{tabular}{c|c|c|c|c|c|c|c}
\hline Bateladas & $\begin{array}{c}\mathbf{S}_{\mathbf{0}} \\
(\mathbf{g} / \mathbf{L})\end{array}$ & $\begin{array}{c}\mathbf{t} \\
(\mathbf{h})\end{array}$ & $\begin{array}{c}\mathbf{X}_{\mathbf{f}} \\
(\mathbf{g} / \mathbf{L})\end{array}$ & $\begin{array}{c}\mathbf{E t a n o l} \\
(\mathbf{g} / \mathbf{L})\end{array}$ & $\begin{array}{c}\mathbf{Y}_{\mathbf{X} / \mathbf{S}} \\
(\mathbf{g} / \mathbf{g})\end{array}$ & $\begin{array}{c}\mathbf{Y}_{\mathbf{P} / \mathbf{S}} \\
(\mathbf{g} / \mathbf{g})\end{array}$ & $\begin{array}{c}\boldsymbol{\rho} \\
(\boldsymbol{\%})\end{array}$ \\
\hline $\mathbf{1}$ & 80,4 & 12 & 2,9 & 37,6 & 0,036 & 0,470 & 92 \\
$\mathbf{2}$ & 80,3 & 12 & 3,6 & 37,8 & 0,045 & 0,472 & 92 \\
$\mathbf{3}$ & 80,8 & 12 & 4,3 & 39,3 & 0,054 & 0,49 & 96 \\
\hline
\end{tabular}

$\mathrm{t}$ - tempo final de cultivo; $S_{0}$ - concentração inicial de glicose; $X_{\mathrm{f}}$ - concentração celular final; $Y_{X / S}$ - fator de conversão de glicose em células; $\mathrm{Y}_{\mathrm{P} / \mathrm{S}}$ - fator de conversão de glicose em etanol; $\rho$ - rendimento em etanol em relação ao máximo teórico $(0,511 \mathrm{~g} / \mathrm{g})$.

A membrana cerâmica utilizada foi submetida aos testes de permeação com água antes e depois à sua utilização, com o objetivo foi verificar a completa remoção das células da membrana após a retrolavagem para o reciclo. Confrontando os valores de permeabilidade hidráulica da membrana pós-uso, form constatadas reduções de 62 e $76 \%$ após a primeira e segunda utilização da membrana, respectivamente, evidenciando, assim, a presença de células remanescentes na estrutura da membrana, que não foram removidas pela retrolavagem das mesmas.

O balanço de massa nos dois reciclos está apresentado na Tabela 2. Através desta determinação, foi possível realizar a quantificação das células de Z. mobilis que permaneceram aderidas na estrutura da membrana cerâmica. Em ambos os reciclos, 50\% das células que permeiam através da membrana permaneceram aderidas à estrutura da mesma e não foram removidas pela passagem de água. Foi realizado o cálculo do percentual de fouling, cujos 

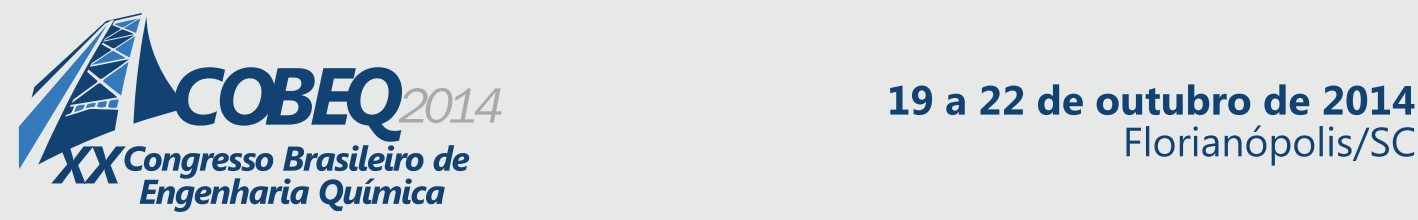

Florianópolis/SC

resultados representaram tendências ao fouling de cerca de 70 e $80 \%$ no primeiro e segundo reciclo, respectivamente, com a utilização da membrana cerâmica.

Tabela 2. Balanço de massa de células de Z. mobilis na permeação pela membrana cerâmica

\begin{tabular}{c|c|c|c|c}
\hline Reciclos & M entra & M permeado & M concentrado & M acumulado \\
\hline 1 & $0,344 \mathrm{~g} / \mathrm{h}$ & 0 & $0,183 \mathrm{~g} / \mathrm{h}$ & $0,161 \mathrm{~g} / \mathrm{h}$ \\
2 & $0,468 \mathrm{~g} / \mathrm{h}$ & 0 & $0,20 \mathrm{~g} / \mathrm{h}$ & $0,268 \mathrm{~g} / \mathrm{h}$ \\
\hline
\end{tabular}

M entra - massa de células a ser permeada; $M$ permeado- massa de céulas que permearam na membrana cerâmica; $\mathrm{M}$ concentrado- massa de células que retornaram ao fermentador após o ciclo de filtração; $M$ acumulado- massa de células que ficaram impregnadas na membrana cerâmica.

\subsection{Fermentação com reciclo de células através de membranas poliméricas}

Assim como realizado com a membrana cerâmica, a etapa de reciclo com as membranas poliméricas foi antecedida pela condução de um cultivo de Z. mobilis para a obtenção de meio fermentado. Este foi permeado pela membrana até seu esgotamento, com velocidade de 1,5.10 $\mathrm{m} / \mathrm{s}$ e pressão de 2 bar. Posteriormente, as células foram recirculadas para o fermentador e o volume completado com o meio de cultura para iniciar uma nova batelada. O tempo de permeação foi de 3,3 horas para o primeiro reciclo e de 4,2 horas para o segundo reciclo.

Como pode ser observado na Tabela 3, não foi verificado o aumento da biomassa entre as bateladas e, como consequência, o mesmo foi revelado em termos de produção de etanol. Isto pode ter sido devido à retenção das células nas fibras constituintes da membrana, impedindo a recirculação para o fermentador e gerando, portanto, reciclo incompleto de células.

Tabela 3. Resultados gerais dos ensaios de fermentação de Zymomonas mobilis com reciclo de células através do módulo de membranas poliméricas $\left(\mathrm{S}_{0}=80 \mathrm{~g} / \mathrm{L}, \mathrm{pH} 5,5,30^{\circ} \mathrm{C}\right)$

\begin{tabular}{c|c|c|c|c|c|c|c}
\hline Bateladas & $\begin{array}{c}\mathbf{S}_{\mathbf{o}} \\
(\mathbf{g} / \mathbf{L})\end{array}$ & $\begin{array}{c}\mathbf{t} \\
(\mathbf{h})\end{array}$ & $\begin{array}{c}\mathbf{X}_{\mathbf{f}} \\
(\mathbf{g} / \mathbf{L})\end{array}$ & $\begin{array}{c}\mathbf{E t a n o l} \\
(\mathbf{g} / \mathbf{L})\end{array}$ & $\begin{array}{c}\mathbf{Y}_{\mathbf{X} / \mathbf{S}} \\
(\mathbf{g} / \mathbf{g})\end{array}$ & $\begin{array}{c}\mathbf{Y}_{\mathbf{P} / \mathbf{S}} \\
(\mathbf{g} / \mathbf{g})\end{array}$ & $\begin{array}{c}\boldsymbol{\rho} \\
(\mathbf{\%})\end{array}$ \\
\hline $\mathbf{1}$ & 80,2 & 12 & 3,3 & 33,8 & 0,041 & 0,422 & 82 \\
$\mathbf{2}$ & 80,4 & 12 & 3,1 & 31,9 & 0,038 & 0,398 & 78 \\
$\mathbf{3}$ & 80,1 & 12 & 3,0 & 29,8 & 0,037 & 0,372 & 73 \\
\hline
\end{tabular}

$\mathrm{t}$ - tempo final de cultivo; $S_{0}$ - concentração inicial de glicose; $X_{\mathrm{f}}$ - concentração celular final; $\mathrm{Y}_{\mathrm{X} / \mathrm{S}}$ - fator de conversão de glicose em células; $\mathrm{Y}_{\mathrm{P} / \mathrm{S}}$ - fator de conversão de glicose em etanol; $\rho$ - rendimento em etanol em relação ao máximo teórico $(0,511 \mathrm{~g} / \mathrm{g})$.

O teste de permeabilidade hidráulica, realizado antes e depois das etapas de reciclo de células de Z. mobilis na membrana polimérica, apontou reduções de 37 e $69 \%$ no primeiro e segundo reciclo, respectivamente. Entretanto, a diminuição do fluxo após a passagem das células de Z. mobilis foi menos acentuada que a obtida com a membrana cerâmica, possivelmente devido à diferença do tamanho dos poros. Amaral et al. (2013), em estudo com membrana polimérica de poli(imida) com tamanho de poro de $0,5 \mu \mathrm{m}$ e área de $0,05 \mathrm{~m}^{2}$, relatam a obtenção de permeabilidade de $127,6 \mathrm{~L} \cdot \mathrm{m}^{-2} \cdot \mathrm{h}^{-1} \cdot \mathrm{bar}^{-1}$. 
O balanço de massa do processo é apresentado na Tabela 4. Nos reciclos efetuados com as membranas poliméricas foi observado o acúmulo de cerca de $80 \%$ das células, isto é, $80 \%$ das células que permearam através das membranas permaneceram aderidas à estrutura das mesmas e não foram removidas pela passagem de água. Esse resultado comprova que, nas condições testadas, a estrutura das membranas poliméricas foi mais suscetível ao fouling, resultante da agregação das células de Z. mobilis do que a estrutura da membrana cerâmica.

Tabela 4. Balanço de massa de células de Zymomonas mobilis na permeação pelo módulo de membranas poliméricas.

\begin{tabular}{c|c|c|c|c}
\hline Reciclos & M entra & M permeado & M concentrado & M acumulado \\
\hline 1 & $0,35 \mathrm{~g} / \mathrm{h}$ & 0 & $0,06 \mathrm{~g} / \mathrm{h}$ & $0,29 \mathrm{~g} / \mathrm{h}$ \\
2 & $0,32 \mathrm{~g} / \mathrm{h}$ & 0 & $0,075 \mathrm{~g} / \mathrm{h}$ & $0,24 \mathrm{~g} / \mathrm{h}$ \\
\hline
\end{tabular}

M entra - massa de células a ser permeada; $M$ permeado- massa de céulas que permearam na membrana polimérica; M concentrado- massa de células que retornaram ao fermentador após o ciclo de filtração; $M$ acumulado- massa de células que ficaram impregnadas na membrana polimérica.

Lee et al. (2013), em estudo sobre o fouling em membranas cerâmicas e poliméricas de microfiltração, sugerem a existência de diferenças críticas nestes processos de microfiltração. Os autores destacam que o fouling nas membranas poliméricas foi superior ao observado em membranas cerâmicas, possivelmente devido a maior natureza hidrofílica das membranas cerâmicas. Os autores afirmam que a maior parte das incrustações verificadas em membranas poliméricas só poderia ser removida por ação de limpezas químicas.

\section{CONCLUSÕES}

Com a utilização de membranas cerâmicas e poliméricas para a separação e concentração de células provenientes do cultivo de Z. mobilis, foi possível a obtenção do caldo permeado isento de células com ambas as técnicas de microfiltração, eliminando, assim, a etapa de dowsntream, tradicionamente efetuada por centrífugas.

Foi verificado que o aumento da biomassa foi mais efetivo quando da utilização da membrana cerâmica. Esse fato pode ser explicado pela dificuldade de retirada das células concentradas nas membranas poliméricas, em função da estrutura de fibras ocas.

Através dos testes de balanço de massa e percentual de fouling, realizados para ambos os módulos, foi observado que incrustação presente na membrana cerâmica tubular foi predominantemente decorrente do fouling irreversível. Na utilização do módulo de membranas poliméricas de fibras ocas, a incrustação predominante foi decorrente de polarização.

\section{APOIO}

CNPQ e UCS 


\section{REFERÊNCIAS}

AMARAL, M. C. S.; ANDRADE, L. H.; LANGE, L.C.; BORGES, C.P. Avaliação do emprego de microfiltração para remoção de fibras do efluente de branqueamento de polpa celulósica. Eng. Sanitária e Ambiental, Belo Horizonte, v.18, n.1, p. 65-74, jan/mar 2013.

CARSTENSEN, F.; APEL, A.; WESSLING, M. In situ product recovery: submerged membranes vs. external loop membranes. J Membrane Sci, 394-395: 1-36, 2012.

DIEL, J. L.; TESSARO, I. C.; MORCELLI, A. S.; CASSINI, A. S.; SILVA, M.K. Caracterização de membranas cerâmicas tubulares. In: XVIII Congresso Brasileiro de Engenharia Química, 2010, Foz do Iguaçu, p. 8211-8220.

ERNANDES, F. Utilização de diferentes substratos para a produção de etanol, levana e sorbitol por Zymomonas mobilis. 2009. 167 f. Tese (Doutorado em Engenharia e Ciência dos Alimentos). Universidade Estadual Paulista Júlio de Mesquita Filho, São José do Rio Preto, São Paulo.

JULBE, A.; FARRUSSENG, D.; GUIZARD, C. Porous ceramic membranes for catalytic reactors - overview and new ideas. J Membrane Sci.181:3-20, 2001.

LEE, S. J.; DILAVER, M.; PARK, P. K.; KIM, J. H. Comparative analysis of fouling characteristics of ceramic and polymeric microfiltration membranes using filtration models. $\mathbf{J}$ Membrane Sci , Georgia, 432 : 97-105, jan.2013.

MALVESSI, E.; CONCATTO, K.; CARRA, S.; SILVEIRA, M.M. Formulation of medium for growth and production of ethanol and intracellular enzymes by Zymomonas mobilis. Braz Arch Biol Tech. 49:139-144, 2006.

MANTTARI, M.; VIITIKKO,K.; NYSTROM, M. Nanofiltration of biologically treated effluents from the pulp and paper industry. J Membrane Sci, 152-160:1-2, 2006.

MILLER, G. L. Use of dinitrosalicylic acid reagent for determination of reducing sugar. Anal Chem, 31:426-428, 1959.

SWINGS, J.; DE LEY, J .The biology of Zymomonas. Bacteriol Rev. 41:1-46, 1977.

VIIKARI, L. Carbohydrate metabolism in Zymomonas mobilis. CRC Critical Rev Biotechnol, 7: 237-261, 1988.

XU, T.J.; ZHAO, X. Q.; BAI, F. W. Continuous ethanol production using self-flocculating yeast in a cascade of fermenters. Enzyme Microb Tech, v.37, p. 634-640, 2005.

WALLBERG, O.; JONSSON, A.;WIMMERSTEDT, R. Ultrafiltration of kraft black liquor with a ceramic membrane. Desalination, 145-153:1-3, 2003. 